\title{
An Inquest of Articles on Online Social Networking Behavior Studies and Its Influence Towards Academic Performance
}

\author{
Maslin Masrom*, Selisa Usat, Jimpele Ambau \\ Razak School of Engineering and Advanced Technology, Universiti Teknologi Malaysia, Jalan Semarak, 54100 Kuala Lumpur, Malaysia \\ *Corresponding author: maslin.kl@utm.my
}

\begin{abstract}
Online Social Networking (OSN) is one of the internet online applications that have grown rapidly in popularity in the recent years. Online Social Networking sites (ONSs) such as Facebook, Twitter, You Tube, Instagram, Keek and others are member-based internet communities that allow users to connect and share their profile information, pictures and videos to communicate with their online members. At this present time, there are few different types of electronic devices such as personal computers, tablets as well as the mobile phones facilitate and make easy millions of these modern use of OSN and the implications of the use behavior of OSN towards the students' academic performance. This study aims to figure whether the OSN has an impact or influence toward academic performance by indicating the numbers of research being done in the past for the said scope. The analysis toward those literatures is done by using three steps which are; identify relevant literature, classify the literatures to the precise category, and synthesize and analyze to meet the study objective. The result shows that not many researches have been done on the said scope throughout the range of six years and this show the limitation of research that likely to be used as reference. It can be concluded that the mentioned scope needed more attention, especially Primary Level. The potential for research study on this matter is vast as the Facebook users growing rapidly.
\end{abstract}

Keywords: Online social networking; behaviour; influence; academic performance; Facebook

(C) 2016 Penerbit UTM Press. All rights reserved

\subsection{INTRODUCTION}

The internet enabled various different types of applications and forms of communication (Ellison et al., 2007). With the massive membership pool of social networking sites (SNSs) confirming that millions of individuals around the globe are open to such innovations particularly teenagers and young adults, or the so-called "Generation M" (Pempek et al., 2009). Online Social Networking (OSN) websites on the internet such as Facebook, Twitter, Youtube, Instagram and others are member-based internet communities that allow users to share their profile information, pictures and to communicate with other in innovative ways such as sending their online status updates as well as conducting a public or private online chat (Pempek et al., 2009). Therefore, internet certainly is a powerful tool that changes the way people communicate with each other and enable us to communicate with each other in much faster, cheaper and more efficient way.

\subsection{BACKGROUND OF THE STUDY}

In the past, social networking was regarded as the physical meeting and interacting of a group of people during their leisure time but this has changed due to the influence of the internet and the study of modern sociology. Today, the nature of gathering has switched from one that was face-to face to one that is virtual through the use of computers connected to the internet (Topper, 2007). The internet technology has grown so rapidly and it has enabled various different types of applications and forms of communication (Ellison et al., 2007). One of the most active and popular internet applications is the OSN. This online application or OSN usage has now becoming everyone's lifestyle including among kids and teenagers. This also has make the communication in this modern society becoming more interesting and furthermore with the recent trend in using hand phones and tablets as its medium, internet usage becoming more prevalence and popular.

Online Social Networking Sites has been defined as web-based services that allow users to construct a public or private profile within a system, a list of users' friends and a view of their list of connections and those made by others within that system (Boyd \& Ellison, 2008). The emerging technologies, especially those referred to as Web 2.0 technologies change the way people access, interact with, create, and share data and information (Ajjan \& Hartshorne, 2008; Dearstyne, 2007; Maloney, 2007; Robbie \& Zeeng, 2008). Popular social network sites in Malaysia are Facebook, YouTube, Friendster and MySpace meanwhile Twitter was the 8th most popular social network in Malaysia (Lim, 2009).

With the massive membership pool of social networking sites, millions of individuals around the globe are open to such innovations particularly teenagers and young adults (Pempek et al., 2009). More involvements among teenagers and young adults on OSN could be because more social involvement during that age. They generally meet more friends and acquaintance when they enter schools or university. 
Facebook was created by students from Harvard University in 2004, which this application is refers to a social networking website. Users who joined the network are able to choose sub-networks based on school, interests, or other characteristics. In July 2007, Facebook was reported to be ranked as the seventh most visited website in the United States (Hirschorn, 2007). Facebook marked its 6th anniversary on February 5, 2010 with a population of 400 million users. On February 11, 2010, the social network hit another milestone as more than 100 million people actively using Facebook on their mobile phones. The numbers of registered users on Facebook have growing more than ten times as in the year of 2014, Facebook reported to have more than 1.15 billion users (Bullas, 2014). There are over 3 billion photos being uploaded to Facebook each month and more than 500,000 active applications on its Platform. FastCompany magazine named Facebook, as the World's Most Innovative Company 2010 (Lim, 2010).

Table 1 shows the most growing countries on using Facebook from January 3, 2012 to July 3, 2012.

Table 1 Most growing countries on facebook

\begin{tabular}{|c|c|c|c|}
\hline Ranking & Country & Number of Users & Percentage Growth \\
\hline 1 & Brazil & $51,172,180$ & $45.55 \%$ \\
\hline 2 & India & $49,807,020$ & $20.31 \%$ \\
\hline 3 & Mexico & $35,611,840$ & $14.91 \%$ \\
\hline 4 & Japan & $10,045,660$ & $60.28 \%$ \\
\hline 5 & Indonesia & $43,831,880$ & $4.92 \%$ \\
\hline 6 & Egypt & $11,342,640$ & $20.78 \%$ \\
\hline 7 & Vietnam & $5,484,120$ & $52.03 \%$ \\
\hline 8 & South Korea & $7,179,540$ & $34.05 \%$ \\
\hline 9 & Thailand & $14,995,720$ & $12,96 \%$ \\
\hline 10 & Germany & $23,750,160$ & $7.37 \%$ \\
\hline 11 & Argentina & $19,036,960$ & $8,28 \%$ \\
\hline 12 & Philippines & $28,259,940$ & $4.54 \%$ \\
\hline 13 & Poland & $8,604,500$ & $14,37 \%$ \\
\hline 14 & Italy & $21,926,160$ & $5.01 \%$ \\
\hline 15 & Colombia & $16,817,080$ & $6,44 \%$ \\
\hline
\end{tabular}

70 per cent of Facebook users are from outside of United States. Whereas in Asia, Facebook is fast becoming the one the region's leading social networks, as Indonesia has the fourth highest number of users in the world, after US, UK and Turkey, with 18.9 million users and the Philippines, the number of Facebook users is 10.5 million. This is followed by India (6.8 million), Taiwan (5.8 million) and Malaysia (5.1 million). In terms of penetration rate, Hong Kong has the highest "Facebook users per country population" rate in Asia, at 39 per cent, followed by Singapore ( 38 per cent), Taiwan ( 25 per cent), Malaysia (18 per cent) and Philippines (11 per cent). In 2010, the total Facebook users in Asia are 59.6 million, or about 15 per cent of the global Facebook population (Lim, 2010). The percentage of Facebook users are growing rapidly from year to year.

In May 2013, statistics shows that some 13.3 million or 45.5 per cent of the total population in the Malaysia are Facebook users. This puts Malaysia on the 8th spot in Asia and 21st place in the world (Mahadi, 2013). Based on Malaysian Communications and Multimedia Commission (MCMC) 2013 Statistic Report, indicated that year-to-year broadband penetration rate in Malaysia has shown a tremendous increase over the past years. The broadband penetration index rate of internet access among Malaysian household (per one hundred household) was recorded as 66.9 per cent in 2013 as compared to 62.3 per cent in 2011 meanwhile the hand phone penetration index rate (per one hundred inhabitants) was increasing to 144 per cent in 2013 as compared to 127.7 per cent in 2011 . The index is expected to rise in few more years to come. It is also stated that based on 2013 statistics, 11 per cent of the internet users are the youngsters below 15 years meanwhile 8.6 percent of the of internet users are in between 15 to 19 years old. In July 2013, there are 13.3 Million Facebook users in Malaysia. Those aged between 18 and 24 are the highest users, contributing 34.5 per cent followed by those aged 25-34 years, which contribute up to 29.5 per cent and 13-17 years (16.3 per cent) (Malaysia Today, 2013). Socialbaker.com 2012 also reported that Internet users in Malaysia view social network sites 14 billion times every month. 80 per cent of Malaysian internet users stream or download videos each month and 51 percent have an active Youtube profile (Socialbakers.com, 2013). Table 2 was extracted from Facebook Advertising page, over a period of two hours on March 1, 2010, showing the Facebook users age groups by country. 
Table 2 Facebook users age groups by country

\begin{tabular}{|l|c|c|c|c|c|}
\hline Country & $13-17$ & $18-24$ & $25-34$ & $35-54$ & $55-64$ \\
\hline Indonesia & $27.25 \%$ & $40.55 \%$ & $22.52 \%$ & $9.01 \%$ & $0.68 \%$ \\
\hline Philippines & $19.25 \%$ & $44.38 \%$ & $23.93 \%$ & $11.40 \%$ & $1.04 \%$ \\
\hline India & $7.64 \%$ & $47.28 \%$ & $31.55 \%$ & $12.26 \%$ & $1.28 \%$ \\
\hline Taiwan & $12.91 \%$ & $31.55 \%$ & $39.81 \%$ & $14.87 \%$ & $0.86 \%$ \\
\hline Malaysia & $15.01 \%$ & $38.32 \%$ & $32.19 \%$ & $13.57 \%$ & $0.91 \%$ \\
\hline Hong Kong & $13.78 \%$ & $29.66 \%$ & $35.08 \%$ & $19.60 \%$ & $1.89 \%$ \\
\hline Thailand & $11.72 \%$ & $38.77 \%$ & $35.86 \%$ & $12.71 \%$ & $0.94 \%$ \\
\hline Singapore & $13.50 \%$ & $30.37 \%$ & $32.52 \%$ & $21.89 \%$ & $1.72 \%$ \\
\hline Pakistan & $10.96 \%$ & $52.11 \%$ & $28.22 \%$ & $7.83 \%$ & $0.88 \%$ \\
\hline Japan & $3.98 \%$ & $26.24 \%$ & $40.94 \%$ & $26.82 \%$ & $2.02 \%$ \\
\hline Vietnam & $12.14 \%$ & $52.77 \%$ & $29.84 \%$ & $4.77 \%$ & $0.49 \%$ \\
\hline Bangladesh & $8.40 \%$ & $50.37 \%$ & $33.57 \%$ & $7.17 \%$ & $0.49 \%$ \\
\hline South Korea & $8.43 \%$ & $29.95 \%$ & $44.52 \%$ & $16.17 \%$ & $0.93 \%$ \\
\hline Sri Lanka & $12.45 \%$ & $43.99 \%$ & $32.82 \%$ & $9.69 \%$ & $1.06 \%$ \\
\hline
\end{tabular}

Socialbakers.com (2012) verified that Malaysian internet users spend almost 20 hours per week online compared with 10.6 hours watching broadcast television. Most of the usage is for entertainment, which equivalent to 87.9 per cent of Malaysian on the internet access Facebook and there are 13,381,120 Facebook users in the Malaysia. 23 per cent of Facebook users login at least 5 times per day (Bullas, 2014).

OSN has draws interest of many scholars and researchers in the recent years due to its popularity among the modern society. There are many articles related to OSN and OSNs studies found in the online journals database and the studies cover various fields and topics of OSN. This study examined the relevant articles that studied on the students' OSN behavior and influence towards academic performance. This study generally focused on one of the most popular OSNs - Facebook. Facebook is undoubtedly one of the most popular and successful OSN (Dickey and William, 2010; Steinfield et al., 2008). The popularity of Facebook use among teenagers and young adults is also part of the reasons why research should be intensified in various topics related to OSN and the influence towards academic performance. OSN is seen making its way into the educational environments when OSN applications have even more potential to further the improve learning and sharing of information among learners and teacher (Ferdig, 2007; Pence, 2007). It is hard to ignore Facebook potential within the education when we consider that many middle school and most high school students are online participating in discussions and groups. Facebook seems to be a natural venue for collaborative, student-led learning (Bosch, 2009). At the same time, we cannot ignore the fact that number of studies in other countries have been done and proven to illustrate of the mixed effects of technology use on academic outcomes. For instance, some studies have found a positive relationship between using technologies with elementary and or high school students and academic outcomes like standardized test scores and course grades (Shapley et al., 2010; Suhr, et al., 2010; Tienken \& Wilson, 2007). Conversely, some studies have found a negative relationship between technology use and academic (Aypay et al., 2007; Waight \& Abd-El-Khalick, 2007). Still other studies have found contradictory positive and negative results. Researchers (Kirschner \& Karpinski, 2010) found that Facebook users reported a lower mean GPA than non-users and Facebook users reported studying fewer hours per week than non-users and study by Junco (2012) found that time spent on Facebook was negatively related to scores on a scale of student engagement. However, some Facebook activities were positively predictive of student engagement, while others were negatively predictive. While not focused on Facebook, a study by Junco, Heiberger, and Loken (2011) supports the thought that online activities matter when examining academic outcomes; the study found that using Twitter in educationally relevant ways led to increases in student engagement. Given these results, it is practical to believe that certain types of Facebook activities matter when examining grades. As we observed, there is lack of consensus in the research of relationship between Facebook and students' academic performance. Reason for the disparity results may be partially due to the fact that the previous studies have been limited by their measures and or sampling designs. Therefore, this paper aims to figure whether the OSN has an impact or influence toward academic performance or not by indicating the relevant and the numbers of research being done in the past for the said area.

However, until now there has been no systematic study of OSN, such as, Facebook and the influence towards academic performance behaviour in the academic literature. Therefore, a structured approached was devised and applied to analytically review the status of OSN literature. The research question for this study is as follows:

RQ1. How is the idea of OSN's behaviour and its influence towards academic performance recognized and reported by researchers?'

An exploration of literature on the earlier mentioned scope is important for the progression and success of OSN in practice and IS academia. This paper contributes two major factors. First, this paper reveals the deficiency of academic literature in the mentioned space; that same 
literature proving a need on OSN behaviour and the influence towards academic performance. Secondly, drawing from the limited existing literature on OSN behaviour, especially research on the usage of Facebook and its influence towards academic performance and present a potential research agenda for future research in the area.

The remainder of this study proceeds as follows. The next section presents the research strategy. Discussion of findings is in the following section. The paper concludes with a summary of the findings and recommendations for future research.

\subsection{METHODOLOGY}

In defining the research method for a comprehensive review of the literature on OSN, two main criteria have to be identified and clarified: (1) the sources, and (2) the search strategy (Cooper, 1998). The sources refer to which outlets are to be targeted, and the search strategy refers to what search terms to utilize during the article extraction process. The aim was to distinguish OSN from an Information System (IS) perspective and to appraise and portray the character of OSN publications in IS. Therefore, the main search was limited to the IS domain.

Thus, this study is specifically devoted to searching and reviewing the literature of previous researches on the influence of OSN behavior towards academic performance and relationship with Facebook usage. Following the research method by Miskon, Bandara, Fielt and Gable (2010) and Levy and Ellis (2006), this study was conducted; first, this study identifies significant literature to the specific category which matches the objective of this study. Secondly, the literatures will be synthesized or amalgamated and analyzed to reach the study objective. The next sections illustrate the segment in detail.

The first segment is identification and extraction of considerable existing literatures with the study. In our basic research methodology, we examined ScienceDirect, ProQuest, Emerald and EBSCOHost online databases. To narrow or contracted the down the relevant literatures, the systematically process of paper extraction will be done by searching the keyword of "Online Social Networking", "Facebook" and "academic performance" in the article title, abstract and also keywords. Beside from scientific journals where searched, researchers also searched articles by getting articles from the scientific conferences. The articles were retrieved are in the six years range, starting from year 2008 until present (June 2014). By setting the year range it helps us to get the latest literatures for this study and also to minimize the irrelevant literatures that could become a stumble that blocked the success of this study. Advanced Search is used to retrieve relevant literatures efficiently. Advanced search is a full search of the entire online database. It finds your term wherever it occurs in the selected online database. This could be in the form of an entry name, part of another word's definition, in a quotation, etc. An Advanced search also allows user to search for words that occur near one another.

In the process of identification and extraction, we have eliminated papers that appeared less focus with the concept of the study or less aligned with the study and because those articles were retrieved from various online databases, we needed to get rid of some duplication papers. Irrelevant papers were excluded from this full text search, to sustain efficiency and feasibility. After filtering process completed, we found 35 articles based on the basic searching in the six years of range. All papers in the mentioned sources were downloaded as full text pdf. files. They were systematically indexed (by year and source) using the Adobe Acrobat professional tool. Adobe Acrobat professional's 'advance-search' facility was used to search the indexed papers. The process of indexing the articles is specifically applied in second segment which comprised of designing and implementing an appropriate classification scheme to match with the study objectives. The overall data analysis and findings are presented in the next section.

\subsection{RESULTS AND DISCUSSION}

This section presents the results of the literature-based analysis. First the extent of the academic IS literature on OSN is discussed and it is argued that more research is warranted. The existing literatures contend that the prime factor in conducting research on OSN is to indicate human behavior while using Facebook and at the same time to discover the relationship between Facebook's users and the influence towards academic performance. However, based on our archival analysis result, we found that there is a lack of academic IS literature on the mentioned scope. It is also a very relevant area of research because of its growing importance in practice. We, therefore, argue that more academic IS research and publications are required discussing OSN in academic institution, in particular in relation to the IS function. We also argue that necessitates more literature of OSN that discoursing in depth about OSN and its influence towards academic performance.

Table 3 shows the numbers of relevant literatures published per year between 2008 and 2014. Online database, such as ProQuest contribute the highest numbers of articles published in the area of Online Social Networking, Facebook and academic performance. Total of 17 articles published between six years of range. EBSCOHost has the lowest number of article published in online database, which only contributed to one article. The article was published in the year of 2012.

Table 3 Numbers of published online social networking papers by year

\begin{tabular}{|c|c|c|c|c|c|c|c|c|}
\hline \multirow{2}{*}{ Online Databases } & \multicolumn{7}{|c|}{ Numbers of Relevant Literatures Per year } & \multirow{2}{*}{ Total } \\
\hline & 2008 & 2009 & 2010 & 2011 & 2012 & 2013 & 2014 & \\
\hline Science Direct & 0 & 0 & 3 & 0 & 7 & 1 & 2 & 13 \\
\hline ProQuest & 1 & 1 & 3 & 6 & 3 & 2 & 1 & 17 \\
\hline Emerald & 0 & 2 & 0 & 1 & 0 & 1 & 0 & 4 \\
\hline EBSCOHost & 0 & 0 & 0 & 0 & 1 & 0 & 0 & 1 \\
\hline & & & & & & & ind Total & 35 \\
\hline
\end{tabular}


Countries such as Tunisia, China, Nigeria, India, South Africa and Australia published one article each on the scope of OSN behavior and its influence towards academic performance. Then country like United Kingdom, contributed two articles or equivalent to 5.70 per cent of overall numbers of relevant articles being published. While Malaysia is the only country in South East Asia that done the research in the mentioned scope, which contributed seven articles in total or 20 per cent out of the overall articles published. Apart from Malaysia, there are two other Asian countries that draw interest and successfully conducting research in the mentioned area. China has published their research paper in the year 2011 and India in the following year. While, North American country, such as United States contributed 57.14 per cent by publishing 20 related researches, mostly in the year 2011 and 2012. Four articles published for the each year are from the following online databases; ProQuest and ScienceDirect.Table 4 is the breakdown of articles published by country from year 2008 until June 2014.

Table 4 Numbers or articles published by country

\begin{tabular}{|l|c|r|}
\hline \multicolumn{1}{|c|}{ Country } & Numbers of Articles Published & Percentage (\%) \\
\hline Tunisia & 1 & $2.86 \%$ \\
\hline United States & 20 & $57.14 \%$ \\
\hline China & 1 & $2.86 \%$ \\
\hline Nigeria & 1 & $2.86 \%$ \\
\hline India & 1 & $2.86 \%$ \\
\hline Malaysia & 7 & $20.00 \%$ \\
\hline South Africa & 1 & $2.86 \%$ \\
\hline Australia & 1 & $2.86 \%$ \\
\hline United Kingdom & 2 & $5.70 \%$ \\
\hline
\end{tabular}

Based on the Figure 1, the percentage of articles published in North America continent is 57.14 per cent, as most of the articles were published in 2011 and 2012. All articles can be found on the following online databases; EBSCOHost, ProQuest, Emerald and ScienceDirect. Malaysia published three articles in 2012 and one paper each in 2010, 2011, 2012 and 2014, followed by China (2011) and India (2012). The total added to 25.72 per cent of overall articles published within the six years of range. North African country, such as Tunisia contributed one article in 2012. The article can be found in EBSCOHost database. South Africa published their article in 2013 and Nigeria in 2011. Both articles were retrieved from ProQuest, a platform that allows users to discover, manage, use and share research gained from authoritative contained, include dissertations and theses. The African continent accumulated 8.57 per cent of articles in total. European country only accrued 5.71 per cent, which contributed by United Kingdom. Two articles were published in 2009 are retrieved from Emerald's database. Australia has the smallest percentage of articles published and discussed on OSN behavior and its influence towards academic performance, 2.86 per cent or equivalent to one article in 2013 (Emerald).

Figure 1 Percentages of articles published by continent

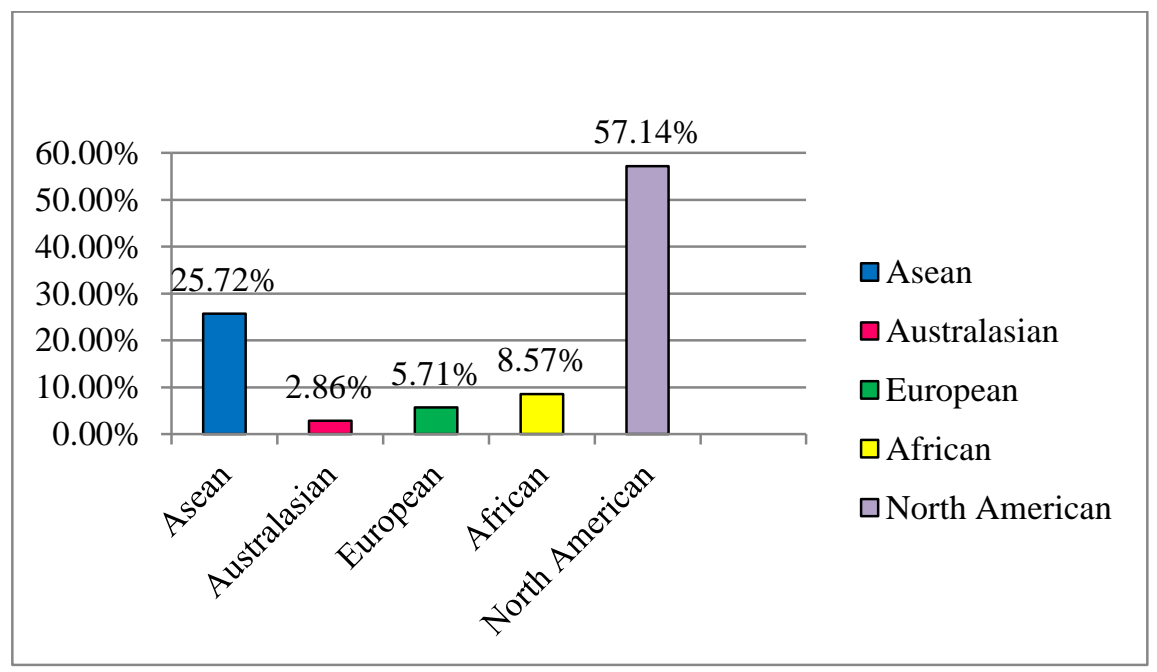

International Standard Classification of Education (ISCED) will be used in order to classified the education levels. ISCED is belong to the United Nations International Family of Economic and Social Classifications. This standard is applied in statistics worldwide with the 
purpose of assembling, compiling and analyzing cross-nationally comparable data. ISCED is the reference classification for organizing education programmes and related qualifications by education levels and fields. ISCED is a product of international agreement and adopted formally by the General Conference of UNESCO Member States (1997). Based on ISCED 1997, there are seven levels of education, which were grouped as follows; Level 0 - Early childhood education (for children aged between three to six years old), Level 1 - Primary education (between seven and ten years of age), Level 2 - Lower secondary education (11 to 15 years old), Level 3 - Upper secondary education (16 to 18 years old), Level 4 - Post-secondary non-tertiary education (17 to 19 years old), Level 5 - Short-cycle tertiary education (19 to 23 years old) and Level 6 - Bachelor's or equivalent level (25 to 27 years old) (ISCED, 1997). For this study, researcher regroups the above education levels into two main groups. The first group is belong to Secondary Level. This particular group is consisting of groups from Level 2, Level 3 and Level 4. The last group is the group from the Tertiary Level. This group is represented by groups who are from Level 5 and Level 6.

Figure 2 Numbers of research conducted

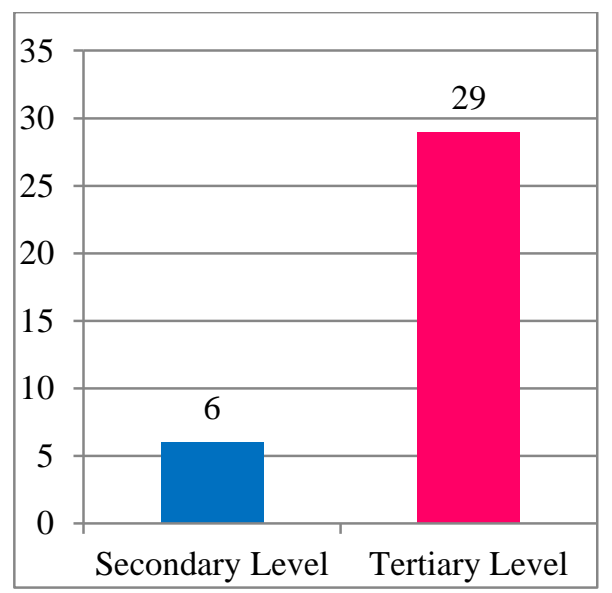

Based on researchers finding, Figure 2 is numbers of research conducted on the two levels of education. From the total of 35 papers from four different online databases, it shows that 17.14 per cent papers were conducted on Secondary Level. Out of the six papers, five research papers were conducted in United States on the mentioned level. Only one research was conducted in Asian continent in 2012, which contributed by India. On the other hand, Tertiary Level which represented by groups from Level 5 and Level 6 gathered the majority of papers published on OSN behavior and its influence towards academic performance. Total of 82.86 per cent or 29 relevant papers were published from year 2008 until June 2014 and these papers can be retrieved from the fours online databases respectively.

\subsection{CONCLUSION}

This study is the attempt to investigate, gather and report on the current study being done on OSN behavior and the influence of Facebook usage towards academic performance in IS academia. It consisted of a very detailed review of IS literature from the four online databases; such as ProQuest, EBSCOHost, Emerald and ScienceDirect. The resulting set of papers showed that the current body of knowledge is still very limited while there is a need for a better understanding of the scope. Major gap between Secondary Level and Tertiary Level in term of research activity in the mentioned scope is crucial, require attention and derived a set of research prepositions that can be investigated further.

The content presented here was a segment of a larger study that attempts to identify the influence of Facebook towards academic performance. Study by Kolek and Saunders (2008) examined student Facebook profiles and found there were no differences in overall GPA between users and nonusers. It is important to note that "non-users" in the Kolek and Saunders (2008) study were those students from a randomly selected sample of the university's student database that researchers could not find on Facebook. These students could have either been non-users or had privacy settings enabled to disallow searching, confounding the results of these findings. Given the few studies available, as well as those studies' conflicting findings and methodological concerns, it is important to re-look at the research's assessment measures and sampling designs. For example, when Junco (2012) incorporate one more variable on what the students do on Facebook (the activities) to check its relationship with their academic performance (since the aforesaid studies have been limited by their measures sampling designs), the data analyses somehow revealed that time spent on Facebook was strongly and significantly negatively related to overall GPA, while only weakly related to time spent preparing for class. Junco actually performed the study by filling a gap in the previous studies by using a large sample $(\mathrm{N}=1839)$ of college students to examine the relationship among multiple measures of frequency of Facebook use, participation in Facebook activities, and time spent preparing for class and actual overall GPA. Indeed vast knowledge can be gathered from various papers, as each paper highlighted different results.

As stated above, this study adopted a three-staged systematic approach; for literature extraction, preparing for analysis and conducting detailed literature analysis, utilising the functionality of a range of tools (i.e. Adobe Acrobat professional, NVIVO and EndNote) was devised and applied here. This study essentially pilot tested the methodology. This three-staged systematic approach can be re-used to cover a broader range of academic outlets to derive a detailed characterization of shared services beyond the IS domain and to obtain a more in-depth understanding of shared services beyond definitions and objectives. 


\section{References}

Ajjan, H., \& Hartshorne, R. (2008). Investigating faculty decisions to adopt Web 2.0 technologies: Theory and empirical tests. Internet and Higher Education, (11), 71-80. doi:10.1016/j.iheduc.2008.05.002.

Aypay A, Erdogan M. \& Sozer M.A. (2007). The variation among schools on classroom practices in science based on TIMSS-1999 in Turkey. Journal of Research Science Teach, 44(10), 1417-1435.

Bosch, T. E. (2009). Using online social networking for teaching and learning: Facebook use at the University of Cape Town. Communication: South African Journal for Communication Theory and Research, 35(2), 185-200.

Boyd, D. M. \& Ellison N. B. (2008). Social Network sites: definition, history and scholarship. Journal of Computer Mediated Communication, 13(11), 210230.

Bullas, J. (2014). 22 Social Media Facts and Statistics You Should Know in 2014. Retrieved from http://www.jeffbullas.com/2014/01/17/20-social-mediafacts-and-statistics-you-should-know-in-2014/

Cooper, H. M. (1998). Synthesizing Research: A Guide for Literature Review. (3rd ed.). Thousand Oak, California: Sage Publications.

Dearstyne, B. W. (2007). Blogs, mashups, \& wikis: Oh, my! The Information Management Journal, 24-33.

Dickey, I. J. and William, F. L. (2010). The evolution (revolution) of social media and social networking as a necessary topic in the marketing curriculum: a case for integrating social media into marketing classes. Society for Marketing Advances Proceedings, June, 140-3.

Ellison, N .B., Steinfield, C. \& Lampe, C. (2007). The benefits of Facebook friends: Social capital and college students' use of online social network sites. Journal of Computer-Mediated Communication, 12(4), 1143-1168.

Ferdig, R. E. (2010). Examining Social Software in Teacher Education. Journal of Technology and Teacher Education, 15(1), 5-10.

Hirschorn, M. (October, 2007). About Facebook. The Atlantic. Retrieved July 1, 2014, from http://www.theatlantic.com/magazine/archive/2007/10/aboutfacebook/6181/

Junco, R. (2012). Too much face and not enough books: The relationship between multiple indices of Facebook use and academic performance. Computer in Human Behavior, 187-198.

Junco, R., Heiberger, G., \& Loken, E. (2012). The effect of Twitter on college student engagement and grades. Journal of Computer Assisted Learning, 119132.

Karpinski, A. C. \& Duberstein, A. (2009). Description of Facebook Use and Academic Performance among Undergraduate and Graduate Students. San Diego, California: American Educational Research Association.

Kirschner, P. A. \& Karpinski, A. C. (2010). Facebook and academic performance. Computers in Human Behavior, 26, 1237-1245.

Kolek, E. A., \& Saunders, D. (2008). Online disclosure: An empirical examination of undergraduate Facebook profiles. NASPA Journal, $45(1), 1-25$.

Levy, Y. \& Ellis, T.J. (2006). A systems approach to conduct an effective literature review in support of information systems research. Informing Science Journal, $9,181-212$

Lim, Y. H. (2009). Snapshot of Social Networking in Malaysia.Grey Review: The Social Web Journal. Retrieved from http://www.greyreview.com/2009/07/28/snapshot-of-social-networking-in-malaysia/

Lim, Y. H. (2010). Fastest Growing Asian Countries on Facebook. Grey Review: The Social Web Journal. Retrieved from http://www.greyreview.com/2010/06/02/fastest-growing-asian-countries-on-facebook/\#more-5910

Mahadi, N. (2013, June 16). 13.3 million M'sians are Facebook users. Borneo Post Online. Retrieved from http://www.theborneopost.com/

Malaysia Today. (2013, September 10). Malaysia social media statistics. Malaysia Today. Retrieved from http://www.malaysia-today.net/malaysia-socialmedia-statistics/

Maloney, E. (2007, Jan. 5). What Web 2.0 can teach us about learning. The Chronicle of Higher Education, 53(18), 26.

Miskon, S., Bandara, W., Fielt, E. and Gable, G. (2010). Understanding shared services: An exploration of the IS literature. International Journal of E-Services and Mobile Applications, Vol. 2(4), pp. 60-75.

Pempek, T. A., Yermolayeva, Y. A., \& Calvert, S. (2009). College students' social networking experiences on Facebook. Journal of Applied Developmental Psychology, 30(3), 227-238.

Pence, H. E. (2007). Preparing for the real web generation. Journal of Educational Technology Systems, 35(3), 347-356.

Robbie, D., \& Zeeng, L. (2008). Engaging student social networks to motivate learning: Capturing, analyzing and critiquing the visual image. The International Journal of Learning, 15(3), 153-160.

Shapley, K. S., Sheehan, D., Maloney, C., \& Caranikas-Walker, F. (2010). Evaluating the implementation fidelity of technology immersion and its relationship with student achievement. Journal of Technology, Learning and Assessment, 9(4). Retrieved 2 August, 2014, from http://escholarship.bc.edu/cgi/viewcontent.cgi?article=1204\&context=jtla

Socialbakers Malaysia Social Media Statistic <http://www.socialbakers.com/all-social-media-stats/facebook/country/malaysia//> Retrieved 19.12.3.

Steinfield, C., Ellison, N.B. \& Lampe, C. (2008). Social capital, self-esteem, and use of online social network sites: a longitudinal analysis. Journal of Applied Developmental Psychology, 29(6), 434-45.

Suhr, K. A., Hernandez, D. A., Grimes, D., \& Warschauer, M. (2010). Laptops and Fourth-Grade Literacy: Assisting the Jump over the Fourth-Grade Slump. The Journal of Technology, Learning, and Assessment, 9(5), 42.

Tienken, C. H., \& Wilson, M.J. (2007). The impact of computer assisted instruction on seventh-grade students' mathematics achievement. Planning and Changing, 38(3), 181-190.

Topper, E. F. (2007). What's new in libraries: Social networking in libraries. New Library World, 108(7/8), 378-380.

United Nations Educational, Scientific and Cultural Organization. (1997). International Standard Classification Of Education (ISCED)1997. Paris, France: Author.

Waight N. \& Abd-El-Khalick, F. (2007). The impact of technology on the enactment of "Inquiry" in a technology enthusiast's sixth grade science classroom. Journal of Research Science Teach, 44(1), 154-182. 